\title{
The contribution of Information and Communication Technologies to the
}

\section{improvement of the adaptive skills and the social inclusion of students with}

\section{intellectual disability}

\author{
A contribuição das Tecnologias de Informação e Comunicação para a melhoria das competências \\ adaptativas e a inclusão social de alunos com deficiência intelectual
}

La contribución de las Tecnologías de la Información y la Comunicación a la mejora de las habilidades adaptativas y la inclusión social de los estudiantes con discapacidad intelectual

Arhondoula Alexopoulou
Mind \& Brain R\&D Net Media Lab, Institute of Informatics and Telecommunications, N.C.S.R. Demokritos, Greece
E-mail: dollyalexopoulou @ gmail.com
Alexandra Batsou
ORCID: https://orcid.org/0000-0002-6649-7828
Mind \& Brain R\&D Net Media Lab, Institute of Informatics and Telecommunications, N.C.S.R. Demokritos, Greece
E-mail: alexmbat@ @yahoo.gr
Athanasios Drigas
ORCID: https://orcid.org/0000-0001-5637-9601
Mind \& Brain R\&D Net Media Lab, Institute of Informatics and Telecommunications, N.C.S.R. Demokritos, Greece
E-mail: dr@iit.demokritos.gr

\begin{abstract}
The contribution of Information and Communication Technologies (ICTs) to the improvement of daily living skills of students with intellectual disability is a topic that has been of great concern to scientists in recent years. In the present systematic review, there has been an attempt to explore the potential of new technologies for the education, the improvement of the adaptive skills and the academic and social inclusion of students with intellectual disability, since they comprise a large part of the population with special educational needs. The review includes research of the last seventeen years on daily living skills, literacy, learning geometric concepts and shapes, focused attention, gross and fine motor skills, and visual-motor coordination. We consider that learning is facilitated with the use of ICTs, as students with intellectual disability are enabled to have equal access to innovative programs, curricula and classroom participation. Moreover, the training and education programs provided through ICTs seem to have a substantial and
\end{abstract} permanent impact on the quality of their lives, finally aiming at their social and vocational inclusion.

Keywords: ICTs; Intellectual disability; Inclusion; Video prompting (VP); Video modelling (VM); Computer-based instruction (CBI); Computer-based video instruction (CBVI); iPad.

\section{Resumo}

A contribuição das Tecnologias da Informação e da Comunicação para a melhoria das habilidades da vida diária de alunos com deficiência intelectual é um tema que tem sido de grande preocupação para os cientistas nos últimos anos. $\mathrm{Na}$ presente revisão, buscou-se explorar o potencial das novas tecnologias para a educação, o aprimoramento das habilidades adaptativas e a inclusão acadêmica e social de alunos com deficiência intelectual, visto que constituem grande parte da população com deficiência intelectual. necessidades educacionais. A revisão inclui pesquisas dos últimos dezessete anos sobre habilidades da vida diária, alfabetização, aprendizagem de conceitos e formas geométricas, atenção concentrada, habilidades motoras grossas e finas e coordenação visual-motora. Consideramos que a aprendizagem é facilitada com o uso das TICs, uma vez que os alunos com deficiência intelectual podem ter igual acesso a programas inovadores, currículos e participação em sala de aula. Além disso, os programas de formação e educação ministrados através das TIC parecem ter um impacto substancial e permanente na qualidade de suas vidas, visando finalmente a sua inclusão social e profissional.

Palavras-chave: TICs; Deficiência intelectual; Inclusão; Solicitação de vídeo (VP); Modelagem de vídeo (VM); Instrução baseada em computador (CBI); Instrução de vídeo baseada em computador (CBVI); iPad. 


\section{Resumen}

La contribución de las Tecnologías de la Información y la Comunicación a la mejora de las habilidades para la vida diaria de los estudiantes con discapacidad intelectual es un tema que ha sido de gran preocupación para los científicos en los últimos años. En la presente revisión se ha intentado explorar el potencial de las nuevas tecnologías para la educación, la mejora de las habilidades adaptativas y la inclusión académica y social de los estudiantes con discapacidad intelectual, ya que comprenden una gran parte de la población con especial necesidades educativas. La revisión incluye investigaciones de los últimos diecisiete años sobre habilidades de la vida diaria, alfabetización, aprendizaje de conceptos y formas geométricas, atención enfocada, habilidades motoras finas y gruesas y coordinación visomotora. Consideramos que el aprendizaje se facilita con el uso de las TIC, ya que los estudiantes con discapacidad intelectual pueden tener acceso equitativo a programas innovadores, currículos y participación en el aula. Además, los programas de formación y educación impartidos a través de las TIC parecen tener un impacto sustancial y permanente en la calidad de sus vidas, apuntando finalmente a su inclusión social y profesional.

Palabras clave: TIC; Discapacidad intelectual; Inclusión; Mensajes de vídeo (VP); Modelado de video (VM); Instrucción basada en computadora (CBI); Instrucción en video basada en computadora (CBVI); iPad.

\section{Introduction}

Awareness of the general difficulties in daily living skills, in the context of the school and wider environment but also in the possibility of vocational training and inclusion faced by a person with a mental disability, has led to an increasing number of studies and literature reviews in recent years. The reason for conducting the present literature review were questions that had already arisen and related to research on the use of ICTs in the field of mental disability in recent years. It has been pointed out since the 1980s, that the use of new technologies in special education creates opportunities for the "integration" of children into society (Dillon, 2004). Moreover, learning with the help of ICTs plays an important role in both typical and nontypical learning environments, since it provides equal opportunities and participation in educational and social development (Istenic Starcic \& Bagon, 2014). All the above motivated our team to investigate the type of protocols that were developed and implemented but also their effectiveness in the key areas of adaptive skills and social inclusion. At first, we thought it appropriate to mention how mental disability is defined, especially after the name change in 2002, and then we explored through the protocols the possibilities offered by ICTs to improve the lives of these people. The systematic review includes research of the last seventeen years on daily living skills, literacy, learning geometric concepts and shapes, focused attention, gross and fine motor skills, and visual-motor coordination, with the implementation of ICT protocols with video prompting, video modelling, computer-based instruction, computer-based video instruction, and through iPad. From the review it was found that the implementation of ICT protocols can improve daily life, achieve inclusion into society and also enable the vocational inclusion of people with intellectual disability.

\section{Methodology}

The article is based on systematic analysis. Initially, the purpose and the objectives of the article were determined and the research questions, which arose from the study of the literature, were raised. All these, presented in the introduction, determined the areas explored through the systematic review and the parts of the article. According to some of the latest systematic protocols (Khan et al., 2001; Wilson \& Lipsey, 2001; Petticrew \& Roberts, 2008; Egger, Davey-Smith, \& Altman, Eds., 2008; Maniglio, 2009; Brettle, 2009; Premlata, 2013; Dadhe, 2016), we developed a protocol on the questions and objectives of the systematic analysis, the criteria for selecting articles, the methodology of finding articles and the results. The following web databases and search engines were used to find the articles: Google Scholar, PubMed, researchgate.net, wiley.com, Springer, sagepub.com and academia.edu. The research was carried out using keywords such as ICTs, intellectual disability, inclusion, video prompting, video modelling, computer-based instruction, computer-based video instruction, iPad, and combinations thereof. The accurate structure, the explanatory writing and especially the complete and documented presentation of the research results played an important role in the selection of the articles. Thesis, articles published before 
2002, unpublished conference proceedings and newspaper articles were excluded (Khan et al, 2001; Petticrew \& Roberts, 2008; Maniglio, 2009). An attempt was made to include a bibliography of recent years, without this meaning that no older existing literature related to the theoretical part of the systematic analysis was utilised. The material included was exclusively from primary sources. The articles used were published entirely in scientific journals and dealt with the subject matter of the work both at the level of theoretical approach and at the level of scientific research. These criteria were applied to all parts of the article.

Finally, a particularly demanding part was the synthesis and analysis of the data that emerged after the literature review, because the primary purpose was to have as much objectivity as possible by utilising the relevant literature. The fact that the work was done by more than one persons at the same time, but independently in the initial stage, reduced the errors and the possibility of using irrelevant material, thus improving the reliability of the findings (Maniglio, 2009). After the evaluation and cross-referencing of the data that emerged from the literature review, followed the processing of the articles. It was deemed necessary through the literature review to record how the researchers had reached the results of their research and how it was possible to describe the procedures followed. All bibliographic references were objective, explaining the methods they used to extract their results, investigating whether their results were verified by similar surveys, and reporting any limitations or concerns.

\section{Intellectual Disability}

The term "intellectual disability" has been used since 2002 (DSM-IV), replacing the former term "mental retardation" (American Psychiatric Association, DSM-IV). According to the American Association for Intellectual and Developmental Disabilities (AAIDD), an individual must have limited mental capacity, adaptive behavioural deficiencies, and manifest the intellectual disability before the age of 18 , to be identified as intellectually disabled. Inadequacy needs to be observed in two or more areas of adaptive skills, namely, home life, social skills, community relations, health, safety, academic skills, leisure and work, as it is pointed out by Katz, Gregorio, and Eduardo Lazcano-Ponce (2008). DSM-5 classifies intellectual disabilities in neurodevelopmental disorders, which are characterised by deficits in cognitive functioning and in social, conceptual and practical skills (APA, 2013). The etiology of intellectual disability includes maternal infections, injuries and poisonings, prenatal alcohol abuse, prenatal nutritional deficiencies and metabolic disorders, prenatal or postnatal lead exposure, injuries during childbirth, traumatic brain injuries, encephalopathies, and childhood brain infections, as it is indicated by the American Association for Intellectual and Developmental Disabilities, the American Psychiatric Association (2013) and Boat, Wu, and National Academies of Sciences, Engineering, and Medicine (2015). Both the American Association for Intellectual and Developmental Disabilities and the American Psychiatric Association (DSM-5) consider intellectual disability in terms of mental capacity and of the intensity of support required for the person. Consequently, the people with intellectual disabilities are classified into four main categories, depending on the degree of support they need. The classification according to the American Association for Intellectual and Developmental Disabilities, the American Psychiatric Association (2013) and Boat et al. (2015) includes:

- mild intellectual disability with IQ range 50-69, which concerns $85 \%$ of the cases

- moderate intellectual disability with IQ range $36-49$, which concerns $10 \%$ of the cases

- severe intellectual disability with IQ range $20-35$, which concerns $3.5 \%$ of the cases

- profound intellectual disability with IQ $<20$, which concerns $1.5 \%$ of the cases 
The severity of the intellectual disability determines the degree of independent living and of functionality in academic, social and professional levels. The individuals with mild disability can live independently with little support, those with moderate disability need moderate level of support, the ones with severe disability need daily support and caring, and finally the profoundly disabled need 24-hour support in all parts of daily living (AAIDD; APA, 2013). Luckily, in the last decades, the opportunities for independent living for people with intellectual disabilities have increased, according to Lipscomb et al. (2017). Moreover, with the help of ICTs, the children with intellectual disability can be educated to achieve academic, professional and social adjustment and inclusion (Wehmeyer, Palmer, Smith, Davies, \& Stock, 2008).

\section{Technological Tools for the Inclusion of Students with Intellectual Disability}

Information and communication technologies support the person with special educational needs in communication, interaction, connection with the learning object, provide reward, motivation and immediate feedback, and finally support the educators, as it is claimed by Lewis and Neil (2001). Moreover, Douglas (2001) points out that ICTs offer opportunities to increase participation in performance-enhancing activities. Bishop (2003) also claims that, ICTs support people with mental and/or social deficits in social communication and participation, and provide a safe environment for them. Especially in the education of university students with special educational needs, the use of ICTs helps them to have easy access and to participate actively in the educational process (Drigas \& Ioannidou, 2013). Therefore, the successful integration of technological tools into learning environments has the potential to benefit all students with special educational needs, especially those with intellectual disabilities. In this way, it becomes easier for them to acquire daily living skills, a thing which leads to greater independence and self-protection. Consequently, the education of children with intellectual disability includes the development of skills in five main categories, drawn from the areas of the adaptive skills: academic knowledge (language, mathematics), social - communication skills, physical integrity - safety, physical and mental health, and professional skills. An educator must take into account all five main categories when preparing a personalised program.

The most common technological tools that facilitate the educational and inclusion process of students with intellectual disability include computers, educational software, video cameras, TVs, projectors, movie projectors, audio players, and interactive whiteboards, among others. Especially a PC activates an intellectually deprived student, as it offers motivation and feedback through the use of image and sound. Most importantly, the student interacts with the computer as he assumes an active role and not a passive one. Moreover, as Yankova and Branekova (2010) claim, the computer with the aid of peripherals becomes useful for students with intellectual disabilities, as it adapts to their specific needs. Scanners that transfer data from paper to the computer screen, large, easy-to-use interactive whiteboards connected to the computer, touch keyboards with large or small keys, and various types of mouse, contribute positively to the educational process. The student is allowed to process each task in small sequential steps that fit his /her learning potential. Finally, for intellectually disabled students with writing and reading difficulties there are available text-to-speech systems, word processing software, on-screen keyboards, and magnifying glasses, which meet their needs and make them active and successful learners (Hasselbring \& Glaser, 2000).

\section{The Use of ICTs for the Improvement of the Adaptive Skills and the Social Inclusion of Intellectually Disabled Individuals Through Research Protocols of the Period 2002-2019}

There has been a lot of research on the use of Information and Communication Technologies (ICTs) in educational settings and consequently on the possibility of training children with intellectual disabilities, aiming at improving their daily living skills. However, there seems to be little research that focuses on reinforcing adaptive behaviour in individuals with intellectual disability without comorbid ASD, as it is stressed by Burns, Lemon, Granpeesheh and Dixon (2019). At this point, 
it is important to be mentioned that $31 \%$ of the people in the autism spectrum disorder are also diagnosed with intellectual disabilities (Baio, Wiggins, Christensen, et al., 2018), a fact which contributes negatively to the development of social skills, among others. According to Burns et al. (2019), the skills that people with intellectual disabilities must integrate properly are mainly daily living skills, which will enable them for proper and adequate self-care. The essential skills that need to be developed, according to AAIDD and DSM-5, include interpersonal skills, such as self-esteem, and the ability to follow rules and to avoid being victimised. Moreover, children with intellectual disabilities in school environments must be able to ask for help from their classmates and the teacher when necessary. They also need to be trained on how to use the television, the radio, and learn to communicate through mobile phones, e-mails, and social media. Then, they have to be trained on conceptual skills, like language and grammatical and numeric literacy. It is important for them to understand the value of money, the payment methods, and manage their time, as well. Last, but not least, intellectually disabled children need to be trained on practical skills (AAIDD; APA, 2013) They need to be able to cope with basic school requirements, for example, the organisation of the school bag, the time of arrival at school, and the appropriate way of dressing. They must also be able to take care of their hygiene, keep themselves safe, keep the area where they live and work clean, and be able to do basic household chores. Finally, it is essential for them to be able to use the public transport. The use of ICTs to achieve effective training on all the skills presented above, with results similar to those achieved through traditional intervention models, comprises a significant feat, as it can be concluded through the study of the existing literature. The present review includes brief presentation of the research of the last seventeen years on the essential living skills, reading, learning geometric concepts and shapes, focused attention, gross and fine motor skills, and visual-motor coordination. The research protocols were implemented through computer-based instruction, computer-based video instruction, video prompting, video modeling, interactive boards, and iPads. The research is presented from 2002 and onwards.

Mechling, Gast and Langone (2002) examined the way computer-based video instruction (CBVI) enables people with intellectual disabilities to read product labels and locate them in the supermarket aisles to buy them. The research involved 4 students with intellectual disabilities, 9-17 years old, who were trained through video simulations, 2-3 times a week. The process was completed in four stages. In the first stage, the students were trained in the use of the program via video and were tested in the ability to read signals, locate three words on a computer screen and locate the corresponding correct items on the supermarket shelf. In the second stage, the researchers presented the students with a list of product images and a list of words. Then, the students had to match the picture with the correct word and vice versa. In the third stage, the students were in a store that they were not familiar with, to see if they could generalise the skills they had learned. In the fourth stage, the researchers asked the students' families to leave their children in the store, in order to locate the products on the shelves from the list they had. The results showed that the students were able to generalise the skills they had learned, after the implementation of the specific intervention program. They were able to read the store signs, and go to the right aisles and locate the right products using pictures and words, in all the stores previously presented in the video.

Mechling, Gast and Barthold (2003) tested an interactive computer program including videos and photos with subtitles, to teach 3 students with moderate intellectual disabilities to make purchases with a debit card and an automatic payment machine. All training sessions were conducted through multimedia computers (computer-based instruction / CBI). The generalisation of the skill was assessed through purchases in community stores. The results showed that the multimedia program was efficient in teaching the students the use of the automatic debit card machine.

Davies, Stock, and Wehmeyer (2003) assessed the use of computer simulation to teach intellectually disabled adults how to use an ATM to access their bank accounts. Nine adults with intellectual disabilities were trained to use the computerbased ATM-SIM. After the short training period, the participants were tested for their ability to operate an actual ATM. The results showed that computer simulation can be used to teach adults with intellectual disabilities a specific skill, in order to 
promote independent living.

Mechling and Cronin (2006) examined the efficiency of computer-based video instruction (CBVI) to teach 3 students with moderate to severe intellectual disabilities how to make orders in fast-food restaurants, using an alternative communication device. The generalisation of the skill was evaluated in community restaurants. The results showed that the ability to make an order increased in 2 of the 3 students, immediately after the intervention using CBVI, while for the third student the ability to make the order increased after the second test. Finally, the ability to perform individually was maintained for each student.

Ayres, Langone, Boon and Norman (2006) tested the efficiency of computer-based instruction (CBI) to train students how to buy goods and pay for them, at a local grocery store. Four, fourteen- year-old students with intellectual disability, were trained in making purchases and payments in a computer simulation environment. The software used was the CD-ROM Project Shop. Before the beginning of the research, the teacher taught the stages of purchase and payment using money in the classroom. Then there was role-playing for the buying process between the teacher and each student. The results of the research proved the method efficient for 3 of the 4 students, as it contributed to the generalisation of skills in a real environment.

Hansen and Morgan (2008) evaluated the results of a computer-based instruction (CBI) curriculum designed to teach grocery shopping skills. The research was conducted in two parts, in the school computer room and at the local grocery store. The CBI included training activities on DVD and CD-ROM. Three videos were presented to each participant for 30 minutes, with a narrator explaining the right and wrong ways to make a purchase. The children were trained with the CD-ROM 4-5 days a week in the computer room, in sessions lasting 30 minutes each. The software included various interactive exercises for the purchasing process. The results showed that after the introduction of CBI, all participants increased the rate of correct answers when buying at the grocery store, while at the same time, skills were generalised to three different grocery stores. The skills retention was also assessed positively, 30 days after the end of the program.

The research of Mechling and Gustafson (2009) aimed to compare the ability of students with moderate intellectual disabilities to complete tasks related to cooking, with the stimulation of static images and with video prompting. The result showed that video prompting (VP) led to a higher success rate (82.6\%) compared to still images (46.7\%).

Ayres and Cihak (2010) evaluated a computer-based video instruction (CBVI) to teach students with intellectual disabilities how to make sandwiches, use a microwave oven, and set the table. The study involved 3 students aged 15, with intellectual disabilities. The software used was "I Can! Daily Living and Community Skills" (Sandbox Learning Company, nd). All CBVI sessions were conducted separately with each student to avoid distractions from environmental stimuli. Initially, the students watched two videos demonstrating a person complete the task. After watching the performance of each skill, the students had the opportunity to test themselves in computer simulation conditions. The results of the research showed that the students acquired all three skills using CBVI. The findings also show that CBVI can be used recurrently by the teacher when the skills are re-evaluated and it turns out that they have been forgotten.

Mechling and Brien (2010) conducted a research to determine the efficiency of the same method, computer-based video instruction (CBVI), to train 3 young adults with moderate intellectual disabilities how to use a bus. All training sessions were conducted in a computer-aided simulation environment, generalising afterwards to a real bus route, and re-evaluating the skill after some time. The students were able to generalise the skill without instruction, while the reassessment showed that they were able to maintain the skill over time. The results of this research confirm once more that CBVI is an efficient teaching tool.

Dekelver and De Boeck (2010) examined whether people with intellectual disabilities can develop ICT-related skills. The study involved people with intellectual disabilities, 6-18 years old. The basic skills of ICTs were instructed to 4 groups. 
The first group was trained on simple functioning skills of a PC such as turning it on-off, using the keyboard and the mouse, and reading a simple message on the screen. The second group developed internet browsing skills. In the third group, the students learned how to write and send e-mails, and in the last group, simple skills for using ICTs in a secure environment were developed. The results showed very high success rates at all the skills trained and students' satisfaction from the use of ICTs.

Cannella-Malone, Fleming, Chung, Wheeler, Basbagill, and Singh (2011) conducted a research in which they instructed two skills of daily living, washing up and using the washing machine, through video modelling and video prompting. They also compared the two intervention methods in terms of efficiency. Seven students aged 11-13, with intellectual disability and other comorbidities such as autism, epilepsy, and deafness, were trained. The research process took place in school rooms, specially designed and equipped with the appropriate materials (the laundry room and the room for washing the dishes). The school staff chose those specific activities as they could help the students gain greater independence in the future. Each activity was analysed in 18 steps, and each step was recorded. During the video prompting process, there were created independent video clips. Each video clip showed a stage of the work while at the same time, a verbal command was heard. In the video modelling process, there was a standalone video that included all 18 steps, with a verbal command at the end of each step. The results showed that video prompting was more efficient than video modelling.

Sahin and Cimen (2011) used an interactive board with specific software in their research. This tool aimed to improve visual-motor coordination, increase the duration of attention and reduce the response time to stimuli. The research was based on a case study concerning a boy with a severe intellectual disability, who completed 11 modules with 60 different tests lasting 15 minutes each. There was an improvement in visual-motor coordination, in attention span and in response time to stimuli. However, the findings of the research cannot be generalised to all students with intellectual disabilities, since each case is different.

Mastrogiannis and Anastopoulos (2012) examined whether the use of "Dynamic Geometry Environments" software by students with intellectual disabilities is efficient in order to understand geometric concepts. Their tool presents the geometric shapes, provides interaction between the student and the geometric objects and enables the student to construct detailed drawings with instant feedback. The research lasted 2 weeks and involved students with intellectual disabilities, 6-14 years old. The results proved that with the repeated use of the computer software, the students became familiar with the geometric concepts and their attention improved. The learning process turned into a game, which maintained their undiminished interest in the targeted geometric concepts. In the end, the students were able to identify, distinguish and name the triangles, the squares, the circles, the rectangles and the lines.

Mechling and Swindle (2013) tested the efficiency of video modelling to improve gross and fine motor skills in 3 students with intellectual disabilities and 3 with ACD. At the same time, a comparison between the two groups was made, in terms of modelling efficiency. Nine different activities were created for gross motor skills and for fine motor skills accordingly. Initially, the students had the opportunity to watch in the video an unknown person performing the activities of gross and fine motor skills. The activities were presented in a different order in each session. Then each of the students had to perform each activity with the given materials, without guidance from the teacher. The results showed that before using the modelling, neither of the two groups of students could complete the activities of gross and fine motor skills, whereas, after the use, the skill of completing the activities improved. The group of students with intellectual disability improved more in both gross and fine motor skills than the group of students with autism. A greater improvement was observed in gross mobility exercises.

Cakmak and Cakmak (2015) aimed at developing interactive shopping skills through the use of iPad, in 3 students with intellectual disabilities and ACD, aged 17-19. The "Shopping Skills Assessment Scale" was used to assess students' 
shopping skills, the "Puppet pals HD little" was used for animation production, and the "Morpho Booth" served to modify students' photographed faces in 3D. There were used two different environments during the research process. One was the classroom, where the intervention program was presented to the students, and the other was a local market supermarket, where the students would be photographed and trained. Besides, all sections of the supermarket were photographed from different angles (corridors, shelves, products, baskets, cash registers). Initially, the researchers showed the students how to activate the two applications on the iPad. After the activation of the applications, each student could see the inside of the supermarket with the aisles, shelves, products, baskets, cash registers, an animation with their face and money for payment. The instructor then showed each student his/her face, asked him/her to read the shopping list and urged him/her to find the products together, touring the supermarket with the movement of the finger. Once they located the products the student wanted to buy, they moved them to the basket and went to the cash register. The cashier welcomed the student, wrote down the product codes, named the price and finally, the instructor paid for the products. The same process was repeated for all the products on the list. In the beginning, the instructor acted as a model for the student. Then the student repeated the process on his own. When needed, he received guidance from the instructor. The results of the intervention using the iPad together with the tools mentioned showed that the number of independent steps for making purchases showed significant progress, namely $100 \%$, for all 3 students. Maintaining shopping skills was tested 5-10 days after training and proved efficient.

Kellems, Mourra, Morgan, Riesen, Glasgow, and Huddleston (2016) developed intervention programs for teaching culinary skills to young adults with intellectual disabilities, using video modelling and video prompting. Specifically, the purpose of the research was to present professional cooks giving step-by-step instructions on cooking, to young people with intellectual disabilities, using VM and VP. It was found that VM is more efficient for shorter and simpler tasks which do not need to be analyzed in small steps, while VP is better to instruct larger and more complex tasks. In addition, VM can be used in people with moderate to severe intellectual disabilities.

Bouck, Satsangi and Bartlett (2017) examined the efficiency of teaching the "grocery selection" through 3 selfoperated audio and video prompting systems (SOPS). Two students over 18, with moderate intellectual disability and other coexisting multiple disabilities, were trained. The students received training and could use all of the three systems provided. The results showed that video prompting is more effective than the other two prompting systems.

Kellems, Rickard, Okray, Sauer-Sagiv and Washburn (2018) evaluated the efficiency of video prompting via iPad for teaching specific daily living skills, such as making pasta and cheese, dining room cleaning, patio cleaning and letter sending. The study involved young adults aged 18-21 with intellectual disabilities. The research was conducted as part of a community living program, which hosted people aged 18-21, in apartments that, in addition to bedrooms, also had fully equipped kitchens. In the first phase of the research, the young people had the necessary materials to perform any work in the natural environment with the supervision, correction and encouragement of the researchers. The researchers then showed the youngsters the use of the iPad, which contained the videos, before proceeding with the intervention. When the young people were ready, they opened the Keynote program and watched the instructions for each step. They also had the opportunity to watch the video each time they encountered difficulties. The results of the research showed that the use of video via iPad was successful in completing the steps of each task, while the young adults maintained the skills even 70 days after the last session, without the auxiliary use of the iPad.

Finally, Kanfush and Jaffe (2019) applied video modelling in educating people with moderate intellectual disability in meal preparation. Four students aged 13-17 with moderate intellectual disability and other co-existing disabilities were trained. During the instruction through video modelling, a model was preparing the food while, at the same time, describing the process step by step. Then, without prompting or reinforcements, the student had to perform the task. The results showed that the success performance rate was $90 \%$, while the skills remained at high levels even after 6 weeks. 


\section{Discussion and Conclusions}

The most important issue for people with intellectual disability according to Brodin (2010), is to master the generalisation of acquired skills, so that training and intervention programs have a substantial and permanent impact on the quality of their lives, aiming at their social and vocational inclusion. The results of all the above research protocols showed that computer simulation, video modelling and video instruction are effective ways to teach many different independent living skills to people with intellectual disabilities. In particular, computer-based video instruction (CBVI) training proved helpful to acquire and generalise daily living skills (Mechling, Gast, \& Langone, 2002; Mechling \& Cronin, 2006; Ayres \& Cihak, 2010; Mechling \& O'Brien, 2010). The method differs from video modelling, in which students watch the model perform the steps and immediately follow the same procedure. Video instruction provides interactive elements in a computer-based simulation environment, in which learners receive instant feedback.

The interactive whiteboard turned out equally helpful as it enabled training on visual-motor coordination and attention (Sahin \& Cimen, 2011). It comprises a very easy-to-use tool, since it adapts to other technological devices and it is possible to add more to its existing functions. Some individuals were also trained successfully in the development of ICT-related skills (Dekelver \& De Boeck, 2010) and the perception of geometric concepts (Mastrogiannis \& Anastopoulos, 2012). Training through multimedia computer simulation (computer-based instruction -CBI) was another effective method for the education and training of people with intellectual disabilities on the generalisation of daily living skills (Mechling, Gast, \& Barthold, 2003; Davies, Stock, \& Wehmeyer, 2003; Ayres et al., 2006; Hansen \& Morgan, 2008). Additionally, the iPad also proved a useful tool in training people with intellectual disabilities on everyday life skills (Cakmak \& Cakmak, 2015). Video prompting training on mobile devices such as the iPad proved effective and time-saving, as well (Kellems et al., 2018). The iPad is more accurate in depicting objects than static images that do not show the objects in their actual shape and size. However, it will still be difficult for a person with an intellectual disability to have an iPad and a supermarket trolley in his hands at the same time, for example, while doing the shopping. Probably, video prompting via iPad would help in a more controlled environment, such as the classroom. Research has also been presented concerning video prompting (Mechling \& Gustafson, 2009; CannellaMalone et al., 2011; Kellems et al., 2016; Bouck, Satsangi, \& Bartlett, 2017), which proved more effective in the education and training of people with intellectual disabilities, compared to the use of static images, audio devices and video modelling (Mechling \& Swindle, 2013; Kanfush \& Jaffe, 2019).

Concluding the review, it can easily be understood that the contribution of ICTs in supporting intellectually disabled people in all areas of the adaptive skills is unquestionable. Information and Communication Technologies help to remove obstacles and thus facilitate the acquisition of independence and autonomy on the part of students. Training and support through ICTs help to remove barriers from the education of students with disabilities (Wehmeyer, Smith, Palmer, Davies, \& Stock, 2004), to achieve the objectives of the curriculum (Brodin, 2010), to strengthen their skills and to increase their selfesteem.

Therefore, we are inclined to believe that it is necessary to work towards a better ICT integration into the learning environments, the design of the curricula and the development of vocational training. We also consider that further research could be conducted concerning interventions through other portable technological devices such as tablets and smartphones, as they are easily accessible and handy and could improve the lives of intellectually disabled people. At the same time, the positive findings of all the research protocols need to be substantiated by larger-scale research, since the intellectually disabled people trained in all research protocols comprise a rather small specimen. 


\section{References}

American Psychiatric Association (APA) Diagnostic and Statistical Manual of Intellectual Disorders, (4th ed.), (DSM-IV). Washington, DC: Author (1994) American Psychiatric Association, (2013). Diagnostic and statistical manual of mental disorders (5th ed.). https://doi.org/10.1176/appi.books.9780890425596 Ayres, K. M., Langone, J., Boon, R. T., \& Norman, A. (2006). Computer-based instruction for purchasing skills. Education and Training in Developmental Disabilities, 41(3), 253.

Ayres, K., \& Cihak, D. (2010). Computer-and video-based instruction of food-preparation skills: Acquisition, generalization, and maintenance. Intellectual and Developmental Disabilities, 48(3), 195-208. https://doi.org/10.1352/1944-7558-48.3.195

Baio, J., Wiggins, L., Christensen, D.L., et al. (2018). Prevalence of Autism Spectrum Disorder Among Children Aged 8 Years — Autism and Developmental Disabilities Monitoring Network, 11 Sites, United States, 2014, MMWR Surveill Summ 2018; 67(SS-6):1-23. http://dx.doi.org/10.15585/mmwr.ss6706a1

Bishop, J. (2003). The Internet for educating individuals with social impairments. Journal of Computer Assisted Learning, 19(4), 546-556. [Google Scholar, wiley.com]

Boat, T. F., Wu, J. T., \& National Academies of Sciences, Engineering, and Medicine. (2015). Clinical characteristics of intellectual disabilities. In Mental disorders and disabilities among low-income children. National Academies Press (US).

Bouck, E. C., Satsangi, R., \& Bartlett, W. (2017). Supporting grocery shopping for students with intellectual disability: a preliminary study. Disability and Rehabilitation: Assistive Technology, 12(6), 605-613. https://doi.org/10.1080/17483107.2016.1201152

Brettle, A. (2009). Systematic reviews and evidence based library and information practice. Evidence Based Library and Information Practice, 4(1), 43-50.

Brodin, J. (2010). Can ICT give children with disabilities equal opportunities in school? Improving schools, 13(1), 99-112. https://doi.org/10.1177/1365480209353483

Burns, C. O., Lemon, J., Granpeesheh, D., \& Dixon, D. R. (2019). Interventions for Daily Living Skills in Individuals with Intellectual Disability: a 50-Year Systematic Review. Advances in Neurodevelopmental Disorders, 1-11.

Cakmak, S., \& Cakmak, S. (2015). Teaching to intellectual disability individuals the shopping skill through iPad. European Journal of Educational Research, 4(4), 177-183. https://doi.org/10.12973/eu-jer.4.4.177

Cannella-Malone, H. I., Fleming, C., Chung, Y. C., Wheeler, G. M., Basbagill, A. R., \& Singh, A. H. (2011). Teaching daily living skills to seven individuals with severe intellectual disabilities: A comparison of video prompting to video modeling. Journal of Positive Behavior Interventions, 13(3), 144-153 https://doi.org/10.1177/1098300710366593

Dadhe, A. (2016). Research methodology. Canada: Kobo Editions..

Davies, D. K., Stock, S. E., \& Wehmeyer, M. L. (2003). Application of computer simulation to teach ATM access to individuals with intellectual disabilities. Education and Training in Developmental Disabilities, 451-456.

Dekelver, J., \& De Boeck, J. (2010). People with intellectual disabilities at risk of eExclusion. In Conference Proceedings eYouth Conference.

Dillon, P. (2004). Trajectories and tensions in the theory of information and communication technology in education. British Journal of Educational Studies, 52(2), 138-150. https://doi.org/10.1111/j.1467-8527.2004.00259.x

Douglas, G. (2001). ICT, education, and visual impairment. British journal of educational technology, 32(3), 353-364.

Drigas, A., \& Ioannidou, R. E. (2013). Special education and ICTs. International Journal of Emerging Technologies in Learning (iJET), 8(2), 41-47. http://dx.doi.org/10.3991/ijet.v8i2.2514

Egger, M., Davey-Smith, G., \& Altman, D. (Eds.). (2008). Systematic reviews in health care: meta-analysis in context. John Wiley \& Sons.

Hansen, D. L., \& Morgan, R. L. (2008). Teaching grocery store purchasing skills to students with intellectual disabilities using a computer-based instruction program. Education and Training in Developmental Disabilities, 43(4), 431-442.

Hasselbring, T. S., \& Glaser, C. H. W. (2000). Use of computer technology to help students with special needs. The Future of Children, $102-122$.

Istenic Starcic, A., \& Bagon, S. (2014). ICT-supported learning for inclusion of people with special needs: Review of seven educational technology journals, 1970-2011. British Journal of Educational Technology, 45(2), 202-230. https://doi.org/10.1111/bjet.12086

Kanfush, P. M., \& Jaffe, J. W. (2019). Using Video Modeling to Teach a Meal Preparation Task to Individuals with a Moderate Intellectual Disability. Education Research International, 2019. https://doi.org/10.1155/2019/1726719

Katz, Gregorio, \& Eduardo Lazcano-Ponce. (2008) Intellectual disability: definition, etiological factors, classification, diagnosis, treatment and prognosis. salud pública de méxico 50.S2, 132-141.

Kellems, R. O., Mourra, K., Morgan, R. L., Riesen, T., Glasgow, M., \& Huddleston, R. (2016). Video modeling and prompting in practice: Teaching cooking skills. Career Development and Transition for Exceptional Individuals, 39(3), 185-190. https://doi.org/10.1177\%2F2165143416651718 
Kellems, R. O., Rickard, T. H., Okray, D. A., Sauer-Sagiv, L., \& Washburn, B. (2018). iPad® video prompting to teach young adults with disabilities independent living skills: a maintenance study. Career Development and Transition for Exceptional Individuals, 41(3), 175-184. https://doi.org/10.1177/2165143417719078

Khan, K. S., Ter Riet, G., Glanville, J., Sowden, A. J., \& Kleijnen, J. (2001). Undertaking systematic reviews of research on effectiveness: CRD's guidance for carrying out or commissioning reviews. 4(2n). NHS Centre for Reviews and Dissemination.

Lewis, A., \& Neill, S. (2001). Portable computers for teachers and support services working with pupils with special educational needs: an evaluation of the 1999 United Kingdom Department for Education and Employment scheme. British Journal of Educational Technology, 32(3), $301-315$.

Lipscomb, S., Hamison, J., Liu Albert, Y., Burghardt, J., Johnson, D. R., \& Thurlow, M. (2017). Preparing for Life after High School: The Characteristics and Experiences of Youth in Special Education. Findings from the National Longitudinal Transition Study 2012. Volume 2: Comparisons across Disability Groups. Full Report. NCEE 2017-4018. National Center for Education Evaluation and Regional Assistance.

Maniglio, R. (2009). The impact of child sexual abuse on health: A systematic review of reviews. Clinical psychology review, $29(7), 647-657$.

Mechling, L. C., \& Cronin, B. (2006). Computer-based video instruction to teach the use of augmentative and alternative communication devices for ordering at fast-food restaurants. The Journal of Special Education, 39(4), 234-245.

Mechling, L. C., \& Gustafson, M. (2009). Comparison of the effects of static picture and video prompting on completion of cooking related tasks by students with moderate intellectual disabilities. Exceptionality, 17(2), 103-116. https://doi.org/10.1080/09362830902805889

Mechling, L. C., \& Swindle, C. O. (2013). Fine and gross motor task performance when using computer-based video models by students with autism and moderate intellectual disability. The Journal of Special Education, 47(3), 135-147. https://doi.org/10.1177/0022466911433859

Mechling, L. C., Gast, D. L., \& Barthold, S. (2003). Multimedia computer-based instruction to teach students with moderate intellectual disabilities to use a debit card to make purchases. Exceptionality, 11(4), 239-254. https://doi.org/10.1207/S15327035EX1104_4

Mechling, L. C., Gast, D. L., \& Langone, J. (2002). Computer-based video instruction to teach persons with moderate intellectual disabilities to read grocery aisle signs and locate items. The Journal of Special Education, 35(4), 224-240.

Mechling, L., \& O'Brien, E. (2010). Computer-based video instruction to teach students with intellectual disabilities to use public bus transportation. Education and Training in Autism and Developmental Disabilities, 230-241.

Petticrew, M., \& Roberts, H. (2008). Systematic reviews in the social sciences: A practical guide. John Wiley \& Sons.

Premlata. (2013). Methodology of social research. Kobo Editions.

Sahin, Y. G., \& Cimen, F. M. (2011). An interactive attention board: Improving the attention of individuals with autism and intellectual retardation. Turkish Online Journal of Educational Technology-TOJET, 10(1), 24-35.

The American Association for Intellectual and Developmental Disabilities (AAIDD), Definition of intellectual disability, https://www.aaidd.org/intellectualdisability/definition

Wehmeyer, M. L., Palmer, S. B., Smith, S. J., Davies, D. K., \& Stock, S. (2008). The efficacy of technology use by people with intellectual disability: A single-subject design meta-analysis. Journal of Special Education Technology, 23(3), 21-30.

Wehmeyer, M. L., Smith, S. J., Palmer, S. B., Davies, D. K., \& Stock, S. (2004). Technology use and people with mental retardation. International review of research in mental retardation, 29, 293-337.

Wilson, D. B., \& Lipsey, M. W. (2001). Practical meta-analysis. Thousand Oaks CA, US: Sage.

Yankova, Z., \& Branekova, D. (2010). Possibilities for application of the informational technologies with the training of children and students with special educational demands. Trakia Journal of Sciences, 8(3), 283-285.

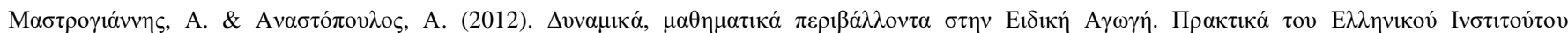

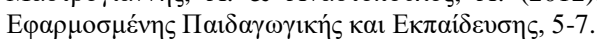

